be simply written off as a "primitive and mutilating procedure." In these times, when balancing the cost benefit equation is increasingly important, to introduce an expensive new treatment for a common condition when an equally effective one already exists cannot be justified unless its benefits are fully examined.

A study of male attitudes to castration as a treatment for cancer is needed and this could well be funded by the drug companies introducing these new preparations.

D A Gillatt

J B M ROBERTS

J C GINGELL

P J B SMITH

Departments of Urology,

Southmead Hospital and the Royal Infirmary,

Bristol BS10 5NB

1 Fallowfield LJ, Baum M, Maguire GP. Effects of breast conservation on psychological morbidity associated with the diagnosis and treatment of early breast cancer. $\mathrm{Br} \mathrm{Med} \mathcal{J}$ $1986 ; 293: 1331-4$

\section{Olfactory hallucinations}

SIR,-Dr N E F Cartlidge states in Any Questions (23 January, p 278) that the commonest cause of olfactory hallucinations is epilepsy. While this may be so in purely neurological practice it is not true in general. The most frequent causes are depression and schizophrenia. In a series of patients with olfactory hallucinations drawn from both neurological and psychiatric clinics a third were depressed, a quarter were schizophrenic, a quarter had an olfactory reference syndrome, and only $8 \%$ had epilepsy.

In depression the hallucination is typically of a foul odour, and two thirds of patients believe this to arise from their own bodies. There are seldom any other sensory abnormalities. The depression is usually endogenous with retardation, depressed mood, and morbid thoughts. Olfactory hallucinations are common in schizophrenia but are often subordinate to hallucinations in other modalities. In late onset paranoid schizophrenia, however, they may be the dominant complaint. Such patients believe the smells are being forced on them and take "reasonable" steps to prevent this by, for example, blocking up chimneys or complaining to the police. In the olfactory reference syndrome the complaint of smell is usually of a true hallucination which the patient believes emanates from himself. It occurs without prior depression of mood and leads to excessive washing of hands, changes of clothes, and avoidance of other people.

In these conditions there is often secondary delusional interpretation, whereas in temporal lobe epilepsy the olfactory hallucinations are almost always recognised by the patient as a subsidiary part of the illness. Patients who present with olfactory hallucinations need careful neurological and mental state examination. The presence of delusions points to a psychiatric syndrome, but the clinician should not lightly dismiss organic causes in patients who have psychiatric symptoms.

\section{P MEATS}

Withington Hospital,
Manchester M20 8LR

1 Pryse-Phillips W. An olfactory reference syndrome. Acta Psychiatr Scand 1971;47:484-509

\section{Transporting critically ill patients by ambulance}

SIR, - Dr J F Bion and colleagues (16 January, p 170) suggest that blood pressure should be monitored during transfer of very ill patients. We would be interested to know how they do this.

Measurement of blood pressure in a moving ambulance is not easy. Automatic measurement of blood pressure by invasive and non-invasive methods requires a still patient. Auscultation of Korotkoff sounds in an ambulance is awkward and frequently impossible. Oscillotonometers are inaccurate in the presence of vibration. The most satisfactory method of measuring systolic blood pressure is by the use of a mercury sphygmomanometer and a finger on the pulse. In the presence of hypotension even this technique is inadequate.

We confess that we are frequently unaware of the precise blood pressure of our patients in transit. Often it is a case of knowing whether or not the patient actually has a blood pressure.

\section{W H KONARZEWSKI} A BANERJEE

Colchester General Hospital,

Colchester CO4 5JL

AUTHOR'S REPLY - We made it clear in our article that no monitoring was employed during transport of the 50 patients in the study. The results suggest that blood pressure monitoring would be a useful aid during ambulance transport of the critically ill, but space did not allow us to elaborate on possible methods.

Intra-arterial blood pressure measurement is the ideal $^{1}$ but requires medical staff competent at inserting cannulas; a cheap and satisfactory monitor is the simple Tycos gauge which displays mean arterial pressure. Non-invasive methods suitable for the critically ill are still at the development stage: the Copal semiautomatic sphygmomanometer (Andrew Stephens Co, Blackpool), the Omega (Vickers), and the Dinamap (Critikon) are available in portable form but overestimate at low pressures. $^{2}$ The Finapres (Ohmeda) represents an important development in accurate and continuous non-invasive pressure measurement, but the device is not yet portable.

Until these problems are resolved critically ill patients should not be transported until they are physiologically stable, ${ }^{3}$ and they should be attended by staff properly trained in resuscitation; intra-arterial cannulation is the most reliable method, and the Tycos gauge the cheapest monitor.

Department of Anaesthetics,

JULIAN BION

Birmingham University,

Birmingham B15 2TH

1 Waddell G, Scott PDR, Lees NW, Ledingham IMcA. Effects of ambulance transport in critically ill patients. Br Med $\mathcal{f} 1975$; i:386-9.

2 Johnson $\mathrm{CJH}$, Kerr JH. Automatic blood pressure monitors. Anaesthesia 1985;40:471-8.

3 Bion JF, Edlin SA, Ramsay G, McCabe S, Ledingham IMcA. Validation of a prognostic score in critically ill patients underValidation of a prognostic score in critically ill going transport. BrMed F 1985;291:432-4.

The future of teaching in district general hospitals in the NHS

SIR,-Professor Harold Ellis (16 January, p 152) casts doubt on the ability of private medicine to provide the basic requirements for teaching senio house officers and registrars.

I have just resigned from the NHS to go into the private sector 15 years before my due date of retirement as a result of the draconian cuts which have been forced on us in the Bromsgrove and Redditch District. These cuts have reduced our senior house officers by one and have completely swept aside a training post in knee surgery which had been set up as part of the training rotation from the Robert Jones and Agnes Hunt Hospital at Oswestry.

The job description for the "fellow in knee surgery" had created a timetable in which the incumbent trainee was exposed to a maximum amount of knee surgery, including arthroscopic surgery, and spent most of his time in outpatients dealing with new and follow up cases of knee problems. This arrangement has now become impossible owing to the drastic cuts in funding in our district and the closure of our specialist orthopaedic hospital at Hill Top, Bromsgrove. The concomitant reduction in senior house officer staffing levels has meant that the teaching post has now become a common or garden NHS senior house officer post.

Furthermore, owing to the changes in staffing levels of registrars and senior house officers after the recommendations in Achieving A Balance we are now left with one registrar, four senior house officers, and no junior house officers to deal with about 1000 elective major orthopaedic cases a year and roughly the same number of emergencies and minor cases. This in effect means that the senior house officers spend nearly all their time clerking patients on the ward while the registrar and consultants deal with outpatients on their own and there is no time left at all for teaching or for instruction in operative technique.

The monetary restrictions have also prohibited the purchase of several items of diagnostic and therapeutic importance in knee surgery which would improve both the quality of teaching and the experience of the senior house officers during their six month sojourn in trauma and orthopaedics.

A far better deal can be offered in the private sector for the senior house officer or junior registrar who wants six months' training in a surgical or medical specialty. The junior would be attached full time to one or at the most two consultants and would deal in depth with a small number of inpatients (between five and 10 a week) and a similar number of outpatients.

Sophisticated modern equipment is what the private patient today expects in a specialist knee service, where there is no question of not being able to afford computed tomography, arthrograms, video recorded arthroscopies, routine clinical photographs, and so on. Theatre time is far more available, and emergencies are dealt with in the private sector by the consultant with help from his junior.

All this is good grist to the teaching mill, and the consultant in private practice should be encouraged to advertise for top quality juniors with the assurance that with very little effort the full time private surgeon has more to offer than the overworked and underfunded NHS consultant.

ANGUS STROVER

Bromsgrove and Redditch District General Hospital,

Redditch, Worcs B98 7UB

\section{Fraud in medicine}

SIR, - Dr Stephen Lock's leading article (6 February, $p$ 376) suggests two lessons to be learnt from the many accounts of fraudulent publication: the close supervision of young researchers, and the rethinking of the emphasis placed on number of publications. The latter seems likely to be the most effective. Faced with the enormous pressure, not just on juniors but on entire departments, to keep up a "good"-bulky_publications record, it is difficult to see close supervision as a satisfactory solution. The way in which Slutsky managed to involve those who should have been monitoring him shows this. ${ }^{1}$ 